\title{
Adapter Device
}

National Cancer Institute

\section{Source}

National Cancer Institute. Adapter Device. NCI Thesaurus. Code C49808.

A device designed to make different pieces of apparatus compatible. 